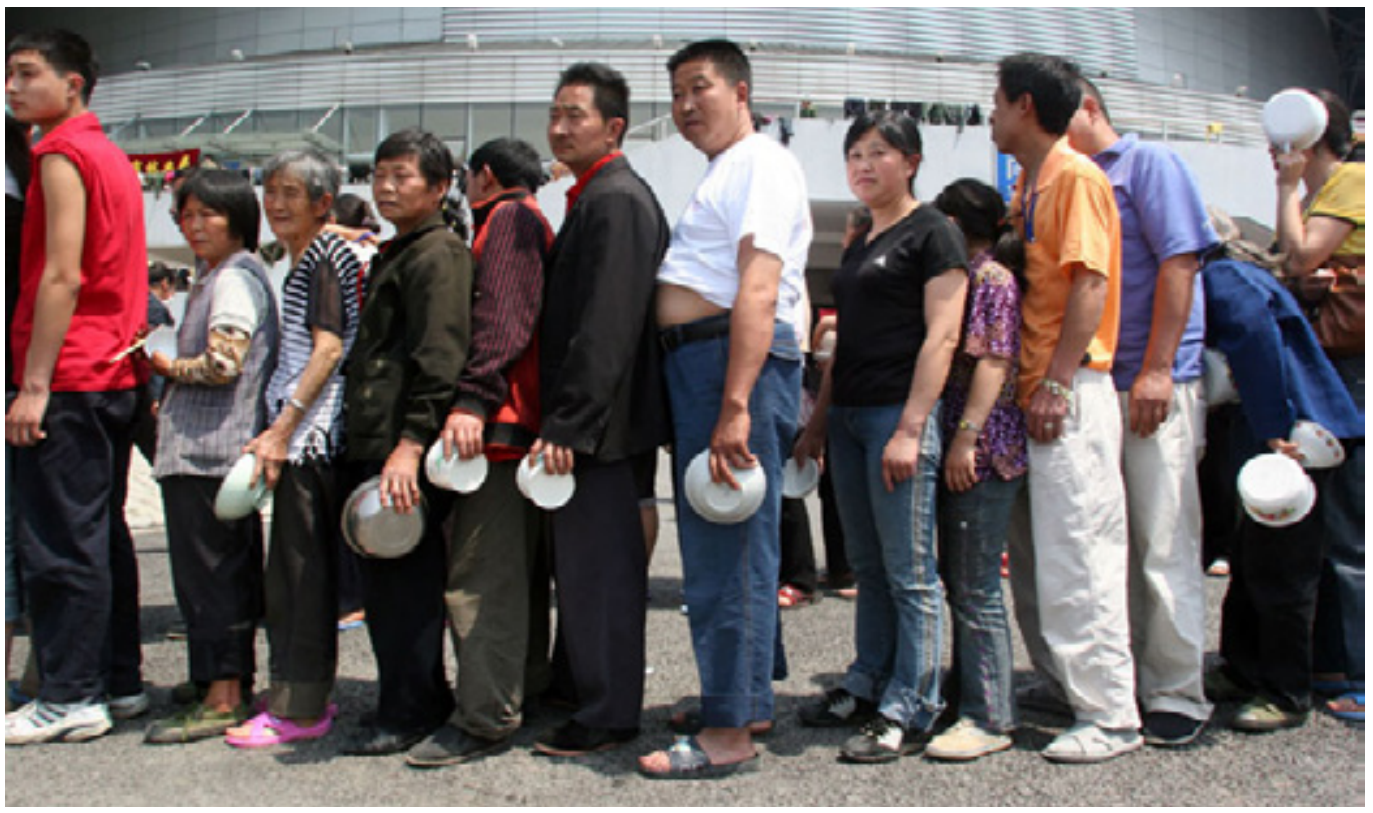

\section{The Power of the}

\section{Square \\ Post-earthquake Activism in Mianyang}

Huan Gao

The year 2008 saw an explosion of civic activities in China, ignited by the devastating earthquake in Sichuan province. Even amid this widespread activism, Mianyang city stood out as a unique site of popular mobilisation, with local people becoming active, self-organised, and creating a network of new NGOs that exists to this day. This kind of activism was a rare thing in Sichuan, where most cities only created new NGOs with the help of external actors. This essay considers how Mianyang's distinctive pattern of local mobilisation was enabled by public spaces, in particular the emergency shelter at Jiuzhou Stadium.
Earthquake survivors line up for food at Jiuzhou stadium in Mianyang. Photo: Raul Vasquez, Flickr.com
T he year 2008 saw an explosion of civic activities in China, ignited by the devastating earthquake in Sichuan province. Countless volunteers, nongovernmental organisations (NGOs), informal associations, and loosely connected Internetbased groups devoted themselves to disaster relief activities (see Xu's essay in the current issue). Even amid this widespread activism, Mianyang city stood out as a unique site of popular mobilisation. Though a poorer city without much civic activity before the earthquake, Mianyang locals became surprisingly active and self-organised, creating a network of new NGOs that exists to this day. This kind of activism was a rare thing in Sichuan, where most cities only created 
new NGOs with the help of external actors. Mianyang's distinctive local mobilisation, I argue, was enabled by public space. In particular, the emergency shelter at Jiuzhou Stadium in Mianyang was a uniquely large, visible, and accessible venue, providing not only the physical site but also a symbolic centre for grassroots mobilisation.

\section{The Jiuzhou Stadium}

Mianyang is an inconspicuous city in Sichuan, located roughly 110 kilometres northwest of the provincial capital, straddling the Longmen Mountains to the west and the Chengdu plain to the east. In 2007 it had a population of 5.38 million, with a per capita GDP of 11,354 yuanjust below the provincial average (Sichuan Bureau of Statistics 2008). The earthquake hit this city especially hard, causing 21,963 deaths, 9,174 missing people, and a total economic loss measuring 25 billion yuan (Sichuan Provincial Government 2009, 17-37 and 52).

In the evening of 12 May, only a few hours after the earthquake, nearby residents began gathering around Jiuzhou Stadium, as the area provided a suitable place to wait out aftershocks. The stadium is a sports multiplex located at the western edge of Fucheng district, the urban core of the city. It sits on a 13.6-hectare lot, with a river running along its northern and the eastern edge, and a major city road to the south. The entire area is large, open, and flat, with multiple structures and carefully manicured lawns and greenery. The structures of the stadium were mostly undamaged by the earthquake.

On the morning of 13 May, as tens of thousands of people who escaped the ruins of Beichuan finally arrived in urban Mianyang amid the pouring rain, the Party secretary of Mianyang decided to let the evacuees take shelter in the stadium. On this first day, over 18,000 people streamed into the structure in the span of a few hours (Heng 2011). Premier Wen Jiabao visited on the afternoon of 13
May, and this exposure may have encouraged other earthquake victims, as more and more homeless individuals from all around Mianyang poured in. Tents filled the lots around the stadium and spilled over to the street and the riverbank area. Though emergency shelters were continuously being set up around Mianyang, Jiuzhou Stadium remained flooded with evacuees. One week after the earthquake, at its busiest, it housed between forty and fifty thousand people, based on different estimates (Zhou 2010, 198; Beichuan County Government $2016,301)$. It was the largest emergency shelter in all of Sichuan (Zheng, He, and Cao 2008). The bulk of people only dissipated towards the end of May, but the stadium did not fully empty until more than a month and a half after the earthquake, on 29 June. Even in the relatively calm last week of June, it housed over three thousand evacuees. The crowd at Jiuzhou was the single largest public gathering created by the earthquake, and it provided the site and the means for robust popular activities.

\section{Organisational Challenges}

Tens of thousands of desperate people housed in one stadium meant to hold less than six thousand created enormous challenges for the city. From preventing communicable diseases to managing waste disposal, everything became disproportionately difficult given the population density. The situation was made even more chaotic by waves of reporters, volunteers, support personnel, and local people looking for lost family and friends who turned up at the site. The local government of Mianyang dedicated as many resources as it could to the management of the stadium. At first, on 13 May, it sent about four hundred city employees (Mianyang Local Gazetteer Office 2009). In the following days, new personnel were continuously added, and at the peak of activity nearly one thousand city employees worked around the clock at the stadium (Zhou 
2010, 198). In April 2016, an activist who had been a city employee at the time told me: 'For more than a month the Mianyang prefecture government did nothing else; everything was put on hold.' Due to this Herculean effort to manage Jiuzhou Stadium, Mianyang officials did not have spare manpower left to organise volunteers; in fact, they came to depend on self-organised volunteers for crucial services.

Lang, a well-off businesswoman, was among the locals who gathered at the stadium on 13 May. She found utter chaos: newly arrived donations were piling up at every unloading bay, and local people like her who wanted to help milled about aimlessly. Lang went directly to the highest-ranking official on the spot, asking permission to organise volunteers and to help with the reception and distribution of supplies. Officials first wanted the Mianyang Communist Youth League (CYL) to organise volunteers, but when they could not locate CYL officials in the midst of the chaos, Lang obtained permission to organise as she saw fit. With official sanction, the businesswoman quickly rounded up other volunteers and together they received, catalogued, and distributed all the water, food and other supplies they found at one particular unloading bay. Seeing how efficient these self-organised volunteers were, and relieved to have one fewer task to take care of, government officials let Lang's team manage this unloading bay throughout Jiuzhou's tenure as an emergency shelter.

In addition to managing supplies, Lang and other volunteers helped evacuees to start an evening dance group. According to Lang, a few days later, though people were being fed and clothed, they needed something uplifting to do. One evening, she and a few volunteers set up candles and speakers in a lot just across the street from the main structure of the stadium and invited people to join them in folk dances in the makeshift square. When this quickly grew into a nightly gathering with hundreds of people, local officials did not object to the initiative. Lang's activities demonstrated that, in this moment, members of the general public faced remarkably few restrictions when it came to the use of the space around them. After the stadium was cleared of evacuees, Lang's team launched several long-term projects in Mianyang and one year later managed to register a formal NGO. For years, she continued fruitful collaboration with many other local volunteers whom she had first met at the stadium.

In April 2016 I interviewed another activist surnamed Wang. He had started a volunteer team when he was in university, though it had never expanded beyond the campus. On 13 May, after mobile phone service stabilised, he called many of his university friends and together they went to Jiuzhou Stadium. Once there, they also took on the task of receiving and distributing supplies. Unlike Lang, they did not even ask for permission in the midst of the chaos. According to Wang, it was not always smooth sailing, as his team came into conflict with government officials working at the location. However, despite the conflict, they were still permitted to work, as it was impractical for officials to keep them out, given the bustling crowds. Wang's team of volunteers had been on indefinite hiatus since they had left university, but their experience at Jiuzhou Stadium gave them a new boost of energy to resume regular community services and take on new charity projects. In a short time, they became involved with earthquake reconstruction activities and also became a valuable member of Mianyang's newly created NGO scene.

\section{An Ark of Life}

A major public building used as an emergency shelter for more than a month and a half was a rare occurrence in the post-earthquake landscape. To control the chaos, most local officials across the region opted for distributed emergency shelters and for rapidly recreating pre-earthquake communities. For example, the city of Shifang began relocating evacuees to less affected areas close by and had them board with locals in private homes (Deyang Bureau 
of Civil Affairs 2008). Most villagers were eager to help, but their particular volunteerism was situated in private homes: there were no crowds, no unending public activities, and very little media presence. The city of Dujiangyan built pre-fabricated homes in record speed, and evacuees began moving into this temporary housing as early as 23 May. These temporary housing communities were administered by existing village leaders or urban residents' committees; they were closed off to outsiders, constantly patrolled by volunteers and the police force, and every visitor had to sign in and sign out (Dujiangyan Government 2008). Earthquake evacuees in Shifang and Dujiangyan quickly left public spaces and also the public eye. For this reason, it became more difficult for volunteers or NGOs to bring them donations, to offer them counselling, or to organise activities for them. Indeed, NGOs working with earthquake victims in temporary housing communities could only enter by invitation from the local authorities.

This was in stark contrast to Jiuzhou Stadium, which for several weeks remained a highly visible and accessible public space. Doors to the stadium could not be closed, as evacuees in dire need and workers offering essential goods and services were constantly coming and going. Tents spilled into surrounding lots and green space and could hardly be surrounded by a wall. Visits by high-level officials and media attention further increased the cost of forcefully restricting access to the area. Also, due to adverse natural conditions across a large swath of Mianyang, maintaining a high-capacity shelter like Jiuzhou Stadium was helpful for local authorities. As a result, Mianyang residents gained a rare public space. There, volunteers' daily interactions with earthquake victims both encouraged and enabled sustained activism, and their encounter with fellow local activists created the foundation for future collective actions and organisation building.

In the wake of the earthquake, Jiuzhou Stadium acquired a grand and elevated reputation: media reports called it nothing less than an 'ark of life' (shengming fangzhou), and local activists still remember it fondly by that name many years later. While this may be in part state propaganda at work, there is no denying the importance of Jiuzhou, both for disaster relief and the development of NGOs in Mianyang after 2008. Nearly all local activists began their NGO careers at Jiuzhou. While Mianyang NGOs remain constrained by restrictive regulations today and are constantly reshaped by government interference, they still represent something new and authentically grassroots. 